\title{
Knowledge transfer from facilities management to building projects: A typology of transfer mechanisms
}

\author{
Jensen, Per Anker
}

Published in:

Architectural Engineering and Design Management

Link to article, DOI:

10.1080/17452007.2012.669131

Publication date:

2012

Link back to DTU Orbit

Citation (APA):

Jensen, P. A. (2012). Knowledge transfer from facilities management to building projects: A typology of transfer mechanisms. Architectural Engineering and Design Management, 8(3), 170-179.

https://doi.org/10.1080/17452007.2012.669131

\section{General rights}

Copyright and moral rights for the publications made accessible in the public portal are retained by the authors and/or other copyright owners and it is a condition of accessing publications that users recognise and abide by the legal requirements associated with these rights.

- Users may download and print one copy of any publication from the public portal for the purpose of private study or research.

- You may not further distribute the material or use it for any profit-making activity or commercial gain

- You may freely distribute the URL identifying the publication in the public portal

If you believe that this document breaches copyright please contact us providing details, and we will remove access to the work immediately and investigate your claim. 
KNOWLEDGE TRANSFER FROM FACILITIES MANAGEMENT TO

BUILDING PROJECTS: A TYPOLOGY OF TRANSFER MECHANISMS

Per Anker Jensen

Technical University of Denmark

Centre for Facilities Management - Realdania Research

Department of Management Engineering

Produktionstorvet,

Building 424

DK 2800 Lyngby,

Denmark

Tel. +45 45251674

E-mail: pank@man.dtu.dk 


\begin{abstract}
The purpose of this article is to present a typology of mechanisms for knowledge transfer from Facilities Management (FM) to building projects. One of the problems in the building industry is a limited degree of learning. The development of professional FM can be the missing link to bridge the gap between building operation and building design. To fulfill this role facilities managers not only need the necessary competences but also appropriate methods and tools to be able to influence the building project.
\end{abstract}

The research is based on literature reviews as well as various empirical studies. The typology is divided in two parts, both based on mechanisms of knowledge push and knowledge pull. The first part has the main focus on the effectiveness of the building requirements and design by knowledge transfer from FM to building project from the front end. Briefing is a central element in this part. The second part has the main focus on efficiency of building performance and operation by knowledge transfer from FM from the back end. Commissioning is a central element in this part. The typology consists of four mechanisms of front end knowledge transfer and four mechanisms of back end knowledge transfer.

Keywords: Facilities Management, typology, knowledge transfer, building project 


\section{INTRODUCTION}

One of the problems in the building industry is a limited degree of learning from experiences of use and operation of existing buildings, when new building projects are planned. The article is based on the viewpoint that the development of professional Facilities Management (FM) can be the missing link to bridge the gap between building operation and building design. However, FM is still a relatively new profession and many facilities managers do not have the necessary competences to play a constructive role in the planning of building projects. This will gradually change as more and more facilities managers become properly educated, but there is also a need to develop the methods and tools for facilities managers to be able to influence building projects.

The development in building projects has been characterised by increasing complexity due to many new requirements, technologies and materials as well as an increasing number of different parties involved in projects. To introduce considerations for FM in building project is one more element that increases this complexity. It is a well known that information overflow is a major problem in building projects (Kreiner, 2005). Thus, it can be argued that if the building process needs to increase the awareness of FM, it will be on the expense of the awareness of other equally important considerations. However, proponents of building commissioning argues that the systematic process included in commissioning can help to simplify the building process and thereby help to cope better with the complexity (Ágústsson, 2010). 
Having to fight for attention is not a new thing for facilities managers. They have to do that to get awareness among the top management in their organization. Bainbridge and Finch (2009) write about the "attention economy" in an article with the title "Getting the attention the facilities managers deserve”. It is a well known challenge for facilities managers to obtain attention at the strategic level in organizations and to talk the language of top management is seen as crucial to achieve that. When we look at knowledge transfer from FM to building projects it may be even more difficult. There are clear cultural differences between facilities managers, who have a focus on how facilities can support the core business and the people from building companies with a focus on delivering a building project. Johnstone (2007) characterizes the cultural difference between maintenance professionals and building project professionals as farmers and hunters based on a study from the UK. Facilities managers like farmers focus on developing long term relationships, while professionals in building projects like hunters focus on catching the prey by winning new contracts and finalizing projects quickly to get on to the next "victim".

The author has in an earlier article in AEDM presented a first proposal for a typology knowledge transfer from FM to building design based on literature studies and case studies (Jensen, 2009a). In the present article the typology has been further developed with a wider scope on knowledge transfer from FM to building project. The typology was developed by the author based on literature reviews covering theories of FM, knowledge management and building project 
management as well as preliminary results from ongoing research projects being undertaken by the Centre for Facilities Management - Realdania Research at the Technical University of Denmark, which the author is heading.

The typology is divided in two parts, both based on mechanisms of knowledge push and knowledge pull. The first part has the main focus on the effectiveness of the building requirements and design by knowledge transfer from FM to building project from the front end. Continuous briefing is a central element in this part. The second part has the main focus on efficiency of building performance and operation by knowledge transfer from FM from the back end. Commissioning is a central element in this part. The typology consists of four mechanisms of front end knowledge transfer and four mechanisms of back end knowledge transfer.

The article starts with a brief literature review followed by a description of the methodology used in developing the typology. After that the actual typology is presented and discussed. The article is finished with conclusions and plans for further research and development of the typology.

\section{LITERATURE REVIEW}

The earlier article in AEDM included a literature review on the limited literature on knowledge transfer from FM to building design. The present article builds partly on the same literature and the review on that can be seen in 
Jensen (2009a). Therefore, the following literature review is limited to a short number of recent publications on the subject.

There have been strong efforts to increase the knowledge transfer from building projects to building operation particularly in relation to reuse of digital data from building design system to operation and maintenance system or other types of Computer Aided FM systems (CAFM). In Denmark a program of so-called CIS-CAD (Coordinated Information System - Computer Aided Design) was developed in the 1990’s by the Ministry of Housing. It was planned as mandatory for public building clients but it ended up as a guideline with little practical use. Later on a Digital Construction program was launched and from 2008 is became mandatory for state building clients to set requirements for digital handover of information from building project to building operation (Bak, 2009). There have been much less efforts to increase the knowledge transfer the other way - from building operation to building projects.

A research group in the UK has studied Knowledge Management (KM) both in the construction industry (Pathirage et al., 2007) and in facilities organizations (Pathirage et al., 2008), but they do not look at knowledge transfer across these domains. Among their conclusions in relation to the construction industry are that knowledge plays a key role in today's fast-changing business environment and that tacit knowledge has particular strong importance, but it is relatively unexplored and underutilized. In relation to the study of FM the research groups formulates an intellectual capital framework, where knowledge capital 
is based on three components: human capital, customer capital and structural capital. The research concluded by developing the KM maturity stages: recognition of importance, formulation of strategy, implementation of techniques, and evaluation of performance; relating to the three components of intellectual capital.

The barriers for use of FM knowledge in building projects have been investigated in an ongoing research project in Denmark. The results show a number of different barriers which are grouped in project related barriers, structural and legal barriers, competence related barriers, and sociological barriers. A number of possible solutions are also indicated divided in shortterm and long-term. From a case study as part of the same research it is noted that several FM related issues are addressed as part of the different design disciplines' normal tasks, while it seems to be more by chance that issues of interdisciplinary character are addressed. There does not seem to be a systematic way to address such interdisciplinary issues (Hansen et al., 2010). Another ongoing research project investigates how considerations for FM are addressed in Public-Private Partnerships (PPP) projects. The preliminary results shows that involvement of FM providers in PPP consortiums does put FM higher on the agenda during the design process of buildings, but the competences to address the issues are limited and there is no systematic procedure to do so (Kristiansen, 2009).

There have recently been some KM research studies of knowledge transfer between service and design phases in relation to industrial product-service 
systems (Vianello and Ahmed, 2009a and 2009b). They utilize a framework where different forms of cognition are placed in a so-called DIKW hierarchy with Data at the bottom followed by Information and by Knowledge at each their level in the structure of a pyramid with Wisdom at the top. The object of knowledge is is characterized by being either embedded in reservoirs or transferred. The mechanisms of transfer are defined by a sender-receiver framework, initiation mechanisms like push, pull or fixed, strategy of personalization and codification, and the context within and across projects. Among the results are that knowledge transfer mainly occurs across projects within a phase and no codified transfer occur across phases except when critical issues are involved. Furthermore, that knowledge from the later stages of the lifecycle is dynamic and to facilitate the reuse a translation process is required to turn it into more stable knowledge.

\section{METHODOLOGY}

The typology has been developed in several steps. The first part includes what in the typology is called "Front end knowledge transfer from FM to building design” (shown as the left part of figure 1). This part was initially developed in 2008 from a combination of a literature study on the relation between FM and the building process, a major case study with participatory observation on a huge building project for the Danish Broadcasting Corporation and a research project on FM best practice with 36 case studies from Denmark, Norway, 
Sweden, Finland and Iceland as further described in the article (Jensen, 2009a).

The first version included the following four transfer mechanisms:

- Codification of knowledge from building operation, which can increase the awareness among designers.

- Competences among facilities managers, which can increase the awareness among designers.

- Power to ensure that designers take considerations for building operation seriously by using the competences of facilities managers.

- Power to ensure that codified knowledge from building operation is used by the design team.

These are in principle similar to the mechanisms on the left side of figure 1 , but in the present version they have been exemplified more specifically as described later in the article.

An essential aspect of the typology is the concepts of continuous briefing and continuous commissioning (shown in figure 1 and 2). The idea to combine these concepts was developed in the beginning of 2009 as part of the preparation of a paper for a keynote speech on HVAC and FM (Jensen, 2009b). The last part of the typology is called "Back end knowledge transfer from FM to building construction” (shown as the right part of figure 1), and it was based on an analogy to the first part and an idea of symmetry between briefing and commissioning. This was developed in 2009 and part of a conference paper presenting ongoing research in this area (Jensen et al., 2009). 
The whole typology has been further developed for the presentation in this article. The development has taken place in a dialogue with other researchers and practitioners as well as with master students.

\section{THE TYPOLOGY}

The knowledge transfer between FM and the building process is basically seen as a combination of initiations by knowledge push and knowledge pull (Lê, 2007, Vianello and Ahmed, 2009a and 2009b). At the front end of the building process the object of the knowledge mainly concerns the user organisation's requirements in relation to the building to be designed and constructed, while the object of the knowledge at the back end of the building process mainly concerns the performance of the finished building. The front end knowledge is mostly concerned with the effectiveness of the building to make sure that it is fit for purpose, functional, usable and possible to adapt to changing need over time. The back end knowledge transfer is mostly concerned with the efficiency of the building to make sure that it is used and operated with a minimum use of resources.

\section{Mechanisms of front end knowledge transfer}

At the front end, the sender-receiver framework (Vianello and Ahmed, 2009a and 2009b) includes client representatives like facilities managers, users and client consultants as senders and the building design team as receivers. The requirement push from FM at the front end can be divided in a competent 
involvement in the building design or knowledge codification. This distinction is based on the differentiation between a strategy of personalization and codification (Lê, 2007, Vianello and Ahmed, 2009a and 2009b). The term “competent involvement" is used, because research and experience shows that involvement does not have a positive effect unless it is combined with appropriate competences. The requirement pull from building design can be divided in increased awareness among client and/or designers and use of power by clients towards designers or by authorities towards clients and/or designers. This distinction is based on a differentiation between a voluntary demand for knowledge and an enforced demand for knowledge.

The combination of two forms of requirement push and two forms of requirements pull gives four methods of front end knowledge transfer from FM to building design as shown on the left side of figure 1 .

(Insert Figure 1 here)

The four mechanisms of front end knowledge transfer are each described below.

\section{Continuous Briefing}

This mechanism is based on the active involvement of competent facilities managers, users and/or FM consultants in a continuous briefing process during design, which can increase the awareness among clients and designers. The term "continuous briefing” was introduced in Jensen (2006) as a way to 
describe a broader dialogue based briefing process as a contrast to the traditional more delimited and specification focused process. It should be stressed that there is not one unified and generally accepted new way of briefing. Continuous briefing is used to capture various trends. In a recent article in AEDM the term "inclusive briefing" is used instead of continuous briefing (Jensen, 2011).

(Insert Table 2 here)

\section{Project reviews}

This mechanism involves the use of power by clients to ensure that designers take considerations for FM seriously by using the competences of facilities managers and/or FM consultants in control activities like projects reviews. Such project reviews can typically take place after each design phase to check that considerations for FM has been taken into account in an acceptable way and to feedback comments and suggestions for improvements to the design team. Compared with continuous briefing it is a more reactive rather than proactive involvement of FM competences in the design process, but these mechanisms can work in combination.

\section{Detailed briefing}

This mechanism is based on codification of knowledge from facilities managers, users and/or FM consultants to increase the awareness among designers. The FM knowledge can be transferred as detailed written specifications for instance as part of a design brief documentation. This 
resembles the result of the traditional briefing process as described in Jensen (2011). The specifications can also take the form of tools like guidelines, checklists and databases. In procurement of building projects as design and build or PPP this kind of knowledge transfer is more or less mandatory, but depending on the form of collaboration it can be combined with involvement of users and facilities managers like in continuous briefing.

\section{Regulation}

This mechanism involves the use of power to make regulations to ensure that codified knowledge from FM is used by the design team. The mechanism can be used both by authorities and by individual clients. An example is the national building codes, which are mandatory for all clients, for instance requirements in relation to safety, health and energy consumption. The national governments can also make regulations mandatory for state clients or clients of buildings partly financed by the public like social housing. An example of this is that it is mandatory for state clients in Norway and Denmark to use of Life Cycle Costing (LCC) in the planning of building projects (Bjørgberg and Haugbølle, 2005).

\section{Mechanisms of back end knowledge transfer}

At the back end, the sender-receiver framework includes representatives involved in or specialists in building operation like in-house facilities managers, facilities service providers or consultants as senders and representatives from the parties involved in building construction as receivers. The performance pull from FM at the back end can be divided in integration 
and outsourcing. This distinction is based on the common differentiation in organization theory between intra-organisational and inter-organisational relations as well as the differentiation in FM literature between in-house and outsourced activities. The performance push can be divided in extended responsibility and extended control. This distinction is based on the differentiation in management literature between authority relations and agency relations, for instance Milgrom and Roberts (1992).

The combination of two forms of performance pull and two forms of performance push gives four methods of back end knowledge transfer from FM to building construction as shown on the right side of figure 1.

The four mechanisms of back end knowledge transfer are each described below.

\section{Design, build and operate}

This mechanism is based on an integration of design, construction and operation in a consortium (special purpose vehicle) with full responsibility (including economical risks) to deliver purpose built and facilitated accommodation to a client over a long period. This is supposed to give the involved partners incentives to take a life cycle cost perspective and other FM related considerations in the design of the building. PPP projects are typical examples of this but it can also be projects for private clients.

\section{Continuous commissioning}


This mechanism is based on the involvement of experienced facilities managers and/or commissioning consultants in a continuous commissioning process in the design and construction process to ensure that the performance of the building is verified. Building commissioning has developed strongly over the last 30 years in the US and from 1996 all federal building should be delivered with a commissioning process. (Águstsson, 2010). The International Energy Agency, Annex 40 on Commissioning gives this definition of commissioning (Visier, 2004):

"Commissioning is a documented way to diagnose and verify building systems performance, and to propose ways to improve the performance in compliance with owner's or occupant's requests. Commissioning is performed in order to keep the system in optimal condition through the life of the building from viewpoints of environment, energy and facility usage.

The commissioning begins with pre-design phase and can be applied through life of building including all phases, which are pre-design, design, elaboration, construction and operation and occupancy phases.”

Commissioning is usually managed by a commissioning agent or authority, which collaborates with the parties in the design and construction team as well as the FM team. The term: "continuous commissioning” is for instance used in an official American guide book on commissioning (US Dep. of Energy, 2002).

\section{Contractors responsible of operation and maintenance (O\&M)}


This mechanism involves outsourcing of the responsibility (including economical risks) for operation and maintenance of a building or a system in a building to the contractor responsible for its construction over a number of years. In that way the contractors are supposed to have incentives to deliver work of high quality and performance during the construction process, so that they do not have unnecessary faults and defects to repair later on or have to remedy low performance levels. It also gives the contractor incentives to influence the design to make it easier both to construct, operate and maintain the building, but these possibilities depends on procurement method and form of collaboration.

\section{Technical Due Diligence}

This mechanism involves outsourcing of the responsibility (including economical risks) for operation and maintenance, for instance as part of a integrated FM contract to a FM provider, who as part of the handover carry out a technical due diligence to verify the performance of the building over a number of years. The term Due Diligence describes a general duty to exercise care in a transaction. Due Diligence is a process to provide information and evaluations to one or both parties involved in a transaction to reduce the risk involved. Technical Due Diligence is mostly concerned with the physical condition of buildings, while other parts of a Due Diligence process deal with financial, legal, business and environmental issues. Technical Due Diligence is often carried out as part of real estate transactions and business mergers, but it is also used in relation to FM outsourcing where the FM provider takes on the responsibility for operation and maintenance of buildings. This can be the case 
for existing buildings but it can also be used for new buildings. Technical Due Diligence is usually carried out by a group of specialist consultants, and it provides a clear basis for the responsibilities of the FM provider (Jensen and Varano, 2011).

\section{Continuous briefing and commissioning in a life cycles perspective}

A combination of the concept of continuous briefing and continuous commissioning in relation to the development of a company's property portfolio can be illustrated as shown in figure 2 .

(Insert Figure 2 here)

The briefing process takes place during the use of existing building as an ongoing capturing of requirements based on experience and changing needs. When the need for a new building evolves the briefing activity intensifies and has a peak around the start of the design phase, but continues as a dialogue with designers during the design phase and to a certain degree with designers and contractors during construction. When the new building is occupied briefing continues as an ongoing capturing of requirements in the extended portfolio.

The commissioning process has a similar development but with an opposite intensity. During the use of existing buildings it takes places as an ongoing optimization of building performance and when a new building project starts, the commissioning process of ensuring and verifying the performance of the 
new building begins and intensifies during design and construction with a peak, when the new building is occupied. When the initial building performance is verified, the commissioning continues as an ongoing optimisation of the extended portfolio.

\section{DISCUSSION}

The distinction between front end and back end knowledge transfer is based on the distinction between requirements and performance. Such a distinction is less relevant in other industries with more integrated responsibility for delivery than the building industry. In building projects the clients' requirements in relation to for instance energy is transferred into design solutions by design consultants, who calculate the expected energy performance and documents theoretically that it is consistent with the clients' and the building codes' requirements. However, the consultants are seldom made responsible for the actual energy performance of the building during operation. In a traditional form of procurement, the specialist contractors deliver the physical building systems that the consultants have specified. They are responsible for that their part of the system follows the design specifications, but they are not responsible for the overall system performance. The result is that the actual energy performance often exceeds the requirements.

There are examples particularly from integrated procurement of building delivery and operation like PPP projects, that the consultants are made 
responsible for the actual energy performance during operation, because otherwise the FM provider or the consortium will be responsible. Systematic commissioning with involvement of the commissioning authority in the briefing is another way to ensure that the requirements are made so specific that the performance can be verified gradually all the way during design and construction.

Some of the knowledge transfer mechanisms in the typology are very dependent on the way building projects are procured. Procurement of design and build and PPP projects favours codification of requirements with Detailed briefing and makes the use of Continuous briefing less easy. The transfer mechanism Design, build and operate is directly dependent on an integrated procurement including both delivery and operation of a building like in PPP projects. Technical Due Diligence requires a separate procurement of O\&M. Contractor responsible for O\&M can be used with specialist contractors, but the potential problems with interfaces are easier avoided, if a main contractor or design and build contractor is responsible for all O\&M.

Some of the knowledge transfer mechanisms are more proactive than others and some are mostly reactive. In table 1 is shown an attempt to classify the transfer mechanisms according to being proactive, potential proactive and reactive. Involvement of FM competences in Continuous briefing and in Continuous commissioning as well as codification in the form of both Detailed briefing and Regulation are seen as being proactive. The two mechanisms with extended responsibility - Design, build and operate and Contractors 
responsible for O\&M - are seen as potentially proactive, because they are intended to give positive incentives to implement considerations for FM. Projects reviews and Technical Due Diligence are both seen as mostly reactive transfer mechanisms.

(Insert Table 1 here)

There are as mentioned in the literature review a number of barriers for the transfer of knowledge from FM to building projects and one of the most important is lack of competences in relation to understanding considerations for FM among all participants in building projects. The typology only indirectly takes the need for increased competences into account. However, this is a prerequisite both for increased awareness among building clients and designers, for competent involvement of facilities managers and for extended control activities.

One of the conclusions of the KM research on knowledge transfer in industrial product-service systems mentioned in the literature review is that knowledge from the later stages of the lifecycle is dynamic and to facilitate the reuse a translation process is required to turn it into more stable knowledge (Vianello and Ahmed, 2009a and 2009b). This conclusion is likely to be valid for the life cycle of buildings seen as a product-service system with the building as the product delivered by building design and construction and FM as the service delivered during use and operation of the building. This puts facilities managers in a crucial role to capture the knowledge from experience during 
use and operation and undertake the translation process needed to reuse this knowledge during building design and construction. A systematic process of continuous briefing and continuous commissioning is an essential way to capture this knowledge and make the translations, but this process and the tools to support it needs to be much more developed.

\section{CONCLUSIONS}

The typology presents a new way of looking at knowledge transfer from FM to building projects by introducing the concepts of front end and back end knowledge transfer. It also changes the often dominating focus on requirements towards a more balanced view on requirements and performance as complimentary concerns of the building clients, users and facilities managers to achieve both effectiveness and efficiency of facilities.

Multiple strategies are needed to improve the integration of FM in building projects. Building clients must take on a leading role in defining and setting up requirements and procedures. The form of procurements of a building project has as shown important implications on which knowledge transfer mechanisms are relevant or favourable. Involvement of professional facilities managers in the design process is an obvious strategy, but increased awareness and competences are needed both among building clients, designers, contractors and the operational staff. More codification of operational knowledge is also needed as well as education of specialists in briefing and commissioning. 
The typology presented here is not necessarily seen as a final version but as a result which is part of an ongoing development. At the moment the typology in figure 1 is very much divided in the front end and the back end part, but how these two parts relates to each other and can be combined should be clarified. The analogy and symmetry between continuous briefing and continuous commissioning shown in figure 2 gives a relation to the building process over time, which could be a basis for a further development of the whole typology. This could also find inspiration by results from research on industrial productservice systems by looking at building delivery and building use as a productservice system.

The immediate plan for further research is to test and evaluate the typology from the results of two ongoing research project carried out by different researchers but as part of the same research program.

\section{LITERATURE}

Ágústsson, R.Ö., Building Commissioning - Advantages and disadvantages of the process and how it has been applied in Denmark. Master Thesis, Department of Management Engineering, Technical University of Denmark (2010).

Bainbridge, M. and Finch, E. 'Getting the attention the facilities manager deserves’ Facilities, Vol. 27, No. 7/8, (2009) 277-290. 
Bak, H.J., 'Bygnings Informations Modellering og Facilities Management' ('Building Information Modelling and Facilities Management'), Master Thesis, Department of Civil Engineering, Technical University of Denmark (2010).

Bjørberg, S. and Haugbølle, K. (eds.) LCC for byggverk. Nordisk hovedprosjekt - sluttrapport (LCC for Buildings and Constructions. Nordic main project - final report). Report in Danish, Swedish and Norwegian, with summary in English. Danish Building Research Institute, SBi, Hørsholm (2005).

Hansen, A.P., Damgaard, T. and de Haas, H., 'Creating and using FM knowledge in complex building projects', Constructions Matter Conference, Copenhagen Business School, 6-7 May (2010).

Jensen, P.A., 'Continuous briefing and user participation in building projects', in Scheublin, F., Pronk, A., Prins, M., Emmitt, S. and Otter, A.d. (eds), Adaptables '06 - Proceedings of the joint CIB, Tensinett, IASS International Conference on Adaptability in Design and Construction, Volume 3, Eindhoven, 3-5 July, Department of Architecture, Building and Planning, Eindhoven University of Technology (2006) 119-131.

Jensen, P.A., 'Design Integration of Facilities Management: A Challenge of Knowledge Transfer', Architectural Engineering and Design Management, Volume 5, No. 3 (2009a) 124-135.

Jensen, P.A, 'HVAC and Facilities Management - from know-why to knowhow', Cold Climate HVAC Conference, Sisimiut, Greenland, 16-19 March (2009b). 
Jensen, P.A., 'Inclusive Briefing and User Involvement: Case Study of a Media

Centre in Denmark', Architectural Engineering and Design Management, Volume 7, No. 3 (2011) 38-49.

Jensen, P.A., Damgaard, T. and Kristiansen, K.: 'The Role of Facilities Management in Building Projects.' Proceedings of Changing Role '09 Conference, Nordwijk aan Zee, The Netherlands, 6.-9. October (2009).

Jensen, P.A. and Varano, M., 'Technical Due Diligence: A Study of Building Evaluation Practice, Journal of Performance of Constructed Facilities, Vol. 25. No. 3, May June (2011).

Johnstone, S., Hunters and farmers? The HRM implications of product-service in construction, Proceedings from CIB World Congress in Cape Town, 14.-17. May (2007).

Kreiner, K., Knowledge Management Challenges in the Construction Sector, Copenhagen Business School (2005).

Kristiansen, K., 'PPP in Denmark - Are Strategic Partnerships between the Public and Private Part a Way Forward?, in Thomas Ng, S. Wong, J.M.W. and Kumaraswamy, M., Proceeding of the CIB TG 72 PPP Symposium: From 'Revisiting and Rethinking' to 'Revamping and Revitalising' PPPs at The University of Hong Kong 28 February 2009, Hong Kong, Centre for Infrastructure \& Construction Industry Development, The University of Hong Kong (2009) 27-34.

Lê, M.A.T., 'Linking experience and learning: application to multi-project building environments.' Engineering, Construction and Architectural Management, Vol. 14 No. 2 (2007) 150-163. 
Milgrom, P. and Roberts, J, 'Economics, Organization \& Management', Prentice Hall, New Jersey (1992)

Pathrirage, C., Amaratunga, D.G. and Haigh, R.P. 'Tacit knowledge and organisational performance: construction industry perspective', Journal of Knowledge Management. Vol. 11, No. 1 (2007) 116-126.

Pathrirage, C., Haigh, R., Amaratunga, D. and Baldry, D. 'Knowledge management in practices in facilities organizations: a case study', Journal of Facilities Management. Vol. 6, No. 1 (2008) 5-22.

US Dept. of Energy, Continuous Commissioning Guide Book, Federal Energy Management Program (2002).

Vianello, G. and Ahmed, S, 'Knowledge Transfer between Service and Design Phases in the Oil Industry', International Journal on Engineering Design ICED’09, 24 -27 August 2009, Stanford University, California, USA (2009a).

Vianello, G. and Ahmed, S, 'Investigating Knowledge Transfer Mechanisms for Oil Rigs', Proceedings of the ASME 2009 International Design Engineering Technical Conference \& Computers and Information in Engineering Conference, IDETC/CIE 2009, August 30 - September 2, San Diego, California, USA (2009b).

Visier, J.C. (ed.), Commissioning tools for improved energy performance Results of IEA Annex 40, www.commissioning-hvac.org (2004). 
Per Anker Jensen

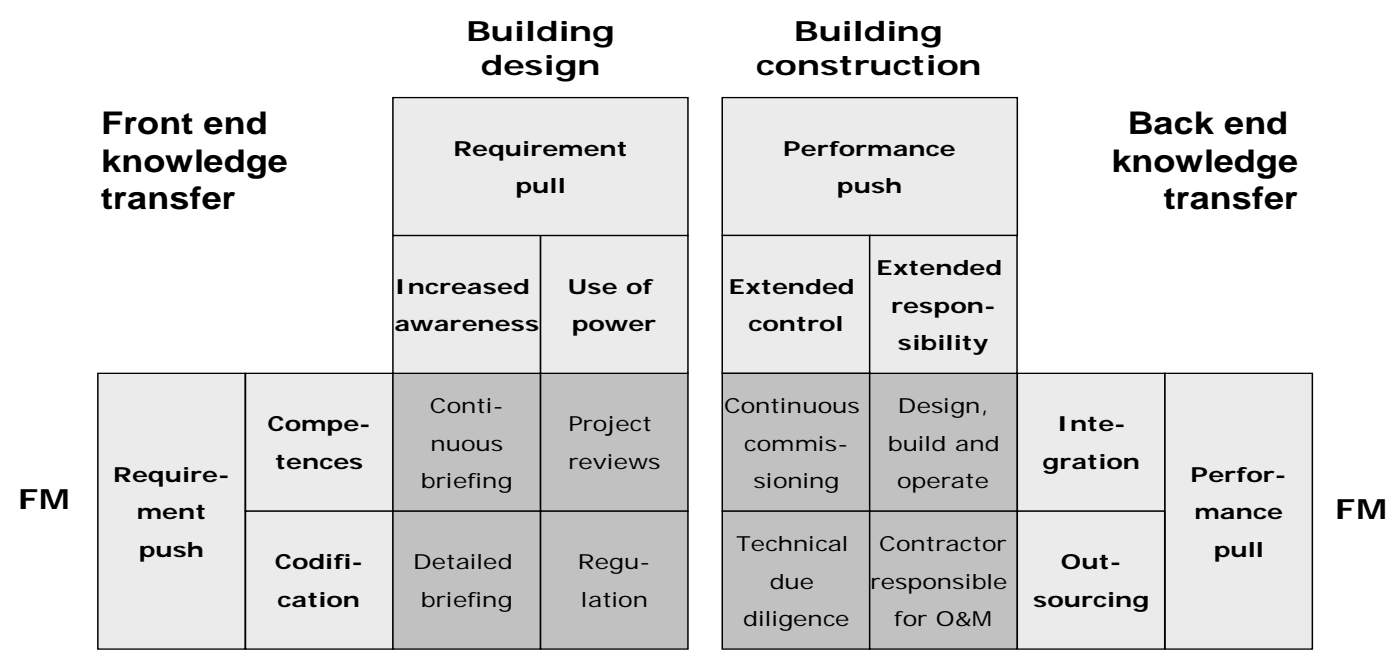

Figure 1: Typology for front and back end knowledge transfer from FM to the building process 
Per Anker Jensen

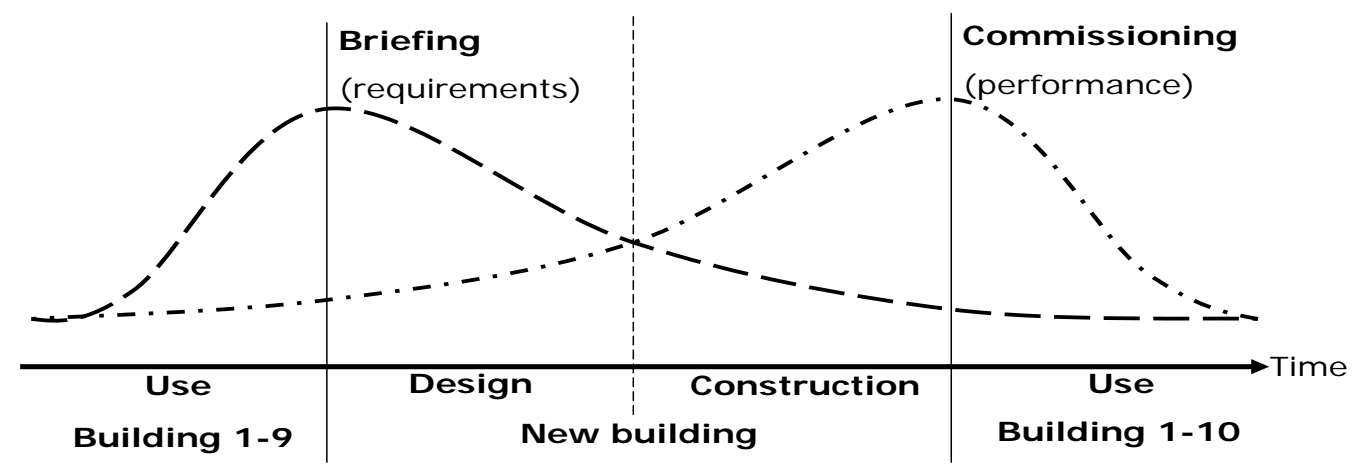

Figure 2: The pincer movement of FM on the building process 
Per Anker Jensen

\begin{tabular}{|l|l|l|}
\hline Proactive & Potentially proactive & Reactive \\
\hline Continuous briefing & Design, build and & Project reviews \\
Detailed Briefing & operate & Technical due diligenc e \\
Regulation & Contractors responsible & \\
Continuous & for O\&M & \\
\hline
\end{tabular}

Table 1: Classification of the knowledge transfer mechanisms 